\title{
Hypertriglyceridemia is an Independent Risk Factor for Development of Impaired Fasting Glucose and Diabetes Mellitus: a 9-year Longitudinal Study in Japanese
}

\author{
Tomio Kametani, Hideo Koshida, Tadasu Nagaoka and Hisatugu MiYakoshi
}

\begin{abstract}
Objective Hypertriglyceridemia is often associated with impaired fasting glucose (IFG) and diabetes mellitus. But the contribution of hypertriglyceridemia to the development of IFG and diabetes mellitus remains unclear. We evaluated whether or not hypertriglyceridemia is a risk factor for the development of IFG and diabetes mellitus.

Methods From 1990 through 1999, 7, 222 Japanese with normoglycemia at baseline were followed. Fasting plasma glucose levels were measured. IFG and diabetes mellitus were defined by ADA criteria.

Result The multivariate-adjusted relative risks for the development of IFG were 1.38 for hypertriglyceridemia $(p=0.001), 1.30$ for obesity $(p=0.003), 1.29$ for hypertension $(p=0.007), 1.26$ for family history of diabetes $(p=0.027)$, and 1.02 for age $(p=0.035)$. The multivariate-adjusted relative risks for the development of diabetes mellitus were 1.003 for triglyceride level $(p=0.013), 1.30$ for level of body mass index $(p=0.003)$, and 2.38 for family history of diabetes (p=0.001).

Conclusion Hypertriglyceridemia is an independent risk factor for the development of IFG and diabetes mellitus in Japanese patients.
\end{abstract}

(Internal Medicine 41: 516-521, 2002)

Key words: hypertension, obesity

\section{Introduction}

Obesity, hypertension, diabetes mellitus, and hypertriglyceridemia are established coronary risk factors. Associations between obesity, hypertension, diabetes mellitus, and hypertriglyceridemia in coronary disease have been reported in many studies (1-4). Impaired fasting glucose defined by the 1997 American Diabetes Association criteria also has a high mortality of ischemic heart disease (5-8). But the recent studies have been reported that impaired glucose tolerance as defined by the 1999 World Health Organization criteria is a risk factor for atherosclerosis, but impaired fasting glucose is not a risk factor $(9,10)$. However, impaired fasting glucose has a high incidence of the development of diabetes (11).

Although these risk factors are related to insulin resistance, the relationships between obesity, hypertension, impaired fasting glucose, diabetes, and hypertriglyceridemia are not clear (12-14). Obesity and insulin resistance are risk factors for the development of hypertension in several cross-sectional and longitudinal studies. Interestingly, hypertension, insulin resistance, and obesity are also risk factors for the development of diabetes mellitus (15-17).

A few studies state that hypertriglyceridemia is a risk factor for the development of impaired fasting glucose and diabetes mellitus (18-20). But there is also a study which showed that hypertriglyceridemia is not risk factor for the development of diabetes mellitus (21). Therefore, we investigated in a prospective study whether hypertriglyceridemia is a risk factor for the development of impaired fasting glucose and diabetes mellitus in the Japanese.

\section{Subjects and Methods}

\section{Subjects}

From January 1990 through December 1999, 14,766 Japanese were examined in the Health Examination Center of Kouseiren Takaoka Hospital, Takaoka City, Japan. Follow-up examinations over the 9-year period were carried out in 7,222 normoglycemic Japanese (3,306 men and 3,916 women) who were aged $18-85$ years at their baseline. The participation rate was $48.9 \%$. The average follow-up was 4.5 years.

\section{Blood pressure measurement}

Blood pressure was determined by a mercury sphygmomanometer in the sitting position. Hypertension was defined as systolic blood pressure $\geqq 140 \mathrm{mmHg}$ or diastolic blood pres-

From the Department of Internal Medicine, Kouseiren Takaoka Hospital, Takaoka

Received for publication June 29, 2001; Accepted for publication February 24, 2002

Reprint requests should be addressed to Dr. Tomio Kametani, the Department of Internal Medicine, Kouseiren Takaoka Hospital, 5-10 Eirakucho, Takaoka, Toyama 933-8555 
sure $\geqq 90 \mathrm{mmHg}$. Also, hypertension was defined as a clinical diagnosis of hypertension with treatment.

\section{Blood examinations}

The subjects gave blood specimens during fasting for 12 hours. The levels of glucose and triglyceride were measured by the enzymatic assay. Impaired fasting glucose and diabetes mellitus were defined by the 1997 American Diabetes Association criteria (22). Impaired fasting glucose was defined as a fasting glucose level of 110-125 mg/dl. Diabetes mellitus was defined as a fasting glucose level of $126 \mathrm{mg} / \mathrm{dl}$ or more. Also, diabetes mellitus was defined as being placed on treatment by a physician. Hypertriglyceridemia was defined as a triglyceride level of $150 \mathrm{mg} / \mathrm{dl}$ or more. Also, hypertriglyceridemia was defined as a clinical diagnosis of hypertriglyceridemia with treatment.

\section{Obesity}

Body mass index (BMI) was calculated as weight in kilograms divided by height in meters squared. Obesity was defined as a BMI level of $25.0 \mathrm{~kg} / \mathrm{m}^{2}$ or more.

\section{Statistical methods}

All statistical analyses were performed with SPSS version 10.1. Differences between hypertriglyceridemic and normotriglyceridemic subjects in baseline characteristics were analyzed using Student's t tests. Multivariate Cox regression models were applied to assess the risk factors for impaired fasting glucose and diabetes mellitus.

\section{Results}

\section{Baseline examination}

Table 1 shows the clinical data of subjects with hypertriglyceridemia and without hypertriglyceridemia at baseline. The mean levels of blood pressure and fasting plasma glucose and BMI of subjects with hypertriglyceridemia and without hypertriglyceridemia were within the normal range. But subjects with hypertriglyceridemia were significantly more obese $(\mathrm{p}<0.001)$ and had significantly higher blood pressure $(\mathrm{p}<0.001)$ and a higher glucose concentration $(\mathrm{p}<0.001)$ than subjects without hypertriglyceridemia.

\section{Risk factors for development of impaired fasting glucose and diabetes mellitus}

Of 7,222 initially normoglycemic subjects, 638 subjects $(8.8 \%)$ developed impaired fasting glucose and 114 subjects (1.6\%) developed diabetes mellitus during the follow-up. In Cox regression model, the cumulative incidences of impaired fasting glucose are $32 \%$ in obesity and $16 \%$ in non-obesity subjects in 9 years (Fig. 1). Otherwise, the cumulative incidences of diabetes mellitus are $8 \%$ in obese and $4 \%$ in nonobese subjects. The relative risks of obesity for the development of impaired fasting glucose and diabetes mellitus are respectively $1.87(95 \%$ CI $1.58-2.21, \mathrm{p}<0.001)$ and $2.12(95 \%$ CI 1.44-3.13, $\mathrm{p}<0.001)$.

The cumulative incidences of impaired fasting glucose are $34 \%$ in hypertensive subjects and $17 \%$ in normotensive subjects (Fig. 2). The cumulative incidences of diabetes mellitus are $7 \%$ in hypertensive subjects and $4 \%$ in normotensive subjects. The relative risks of hypertension for the development of impaired fasting glucose and diabetes mellitus are respectively $2.17(95 \%$ CI $1.53-2.19, \mathrm{p}<0.001)$ and 1.81 (95\% CI $1.18-$ $2.78, \mathrm{p}<0.006)$.

The cumulative incidences of impaired fasting glucose are $33 \%$ in hypertriglyceridemia and $17 \%$ in normotriglyceridemia (Fig. 3). The cumulative incidences of diabetes mellitus are $8 \%$ in hypertriglyceridemia and $4 \%$ in normotriglyceridemia. The relative risks of hypertriglyceridemia for development of impaired fasting glucose and diabetes mellitus are respectively 1.87 (95\% CI 1.57-2.23, p<0.001) and 2.03 (95\% CI 1.34$3.07, \mathrm{p}<0.001)$.

Sex, age, BMI, family history of diabetes, hypertension, cigarette smoking, and fasting plasma glucose at baseline were adjusted. In multivariate-adjusted Cox regression model, age, obesity, hypertension, and hypertriglyceridemia had respectively 1.009 -fold (95\% CI 1.001-1.018, $\mathrm{p}=0.035), 1.30$-fold (95\% CI 1.09-1.55, $\mathrm{p}=0.003), 1.29$-fold (95\% CI 1.07-1.55, $\mathrm{p}=0.007)$, and 1.38 -fold (95\% CI 1.15-1.66, $\mathrm{p}=0.001$ ) risk for development of impaired fasting glucose (Table 2). Obesity, hypertension, and hypertriglyceridemia in multivariate-adjusted Cox regression model of diabetes mellitus did not have a sig-

Table 1. Clinical Data of Subjects at Baseline According to the Baseline Serum Triglyceride Levels

\begin{tabular}{lccc}
\hline & Normotriglyceridemia & Hypertriglyceridemia & p-value \\
\hline $\mathrm{n}(\mathrm{m} / \mathrm{f})$ & $5,999(2,512 / 3,487)$ & $1,223(794 / 429)$ & \\
Age $(\mathrm{yr})$ & $52.3 \pm 10.5$ & $53.3 \pm 10.3$ & $\mathrm{~ns}$ \\
Systolic BP (mmHg) & $118.4 \pm 16.7$ & $122.4 \pm 17.8$ & 0.001 \\
Diastolic BP (mmHg) & $75.6 \pm 10.8$ & $78.8 \pm 10.8$ & 0.001 \\
BMI (kg/m $\left.{ }^{2}\right)$ & $22.6 \pm 2.7$ & $24.4 \pm 2.7$ & 0.001 \\
Fasting plasma glucose (mg/dl) & $90.2 \pm 8.2$ & $92.2 \pm 8.1$ & 0.001 \\
Triglyceride (mg/dl) & $87.3 \pm 27.8$ & $216.9 \pm 85.8$ & 0.001 \\
\hline
\end{tabular}

Values are shown in means \pm SD. 


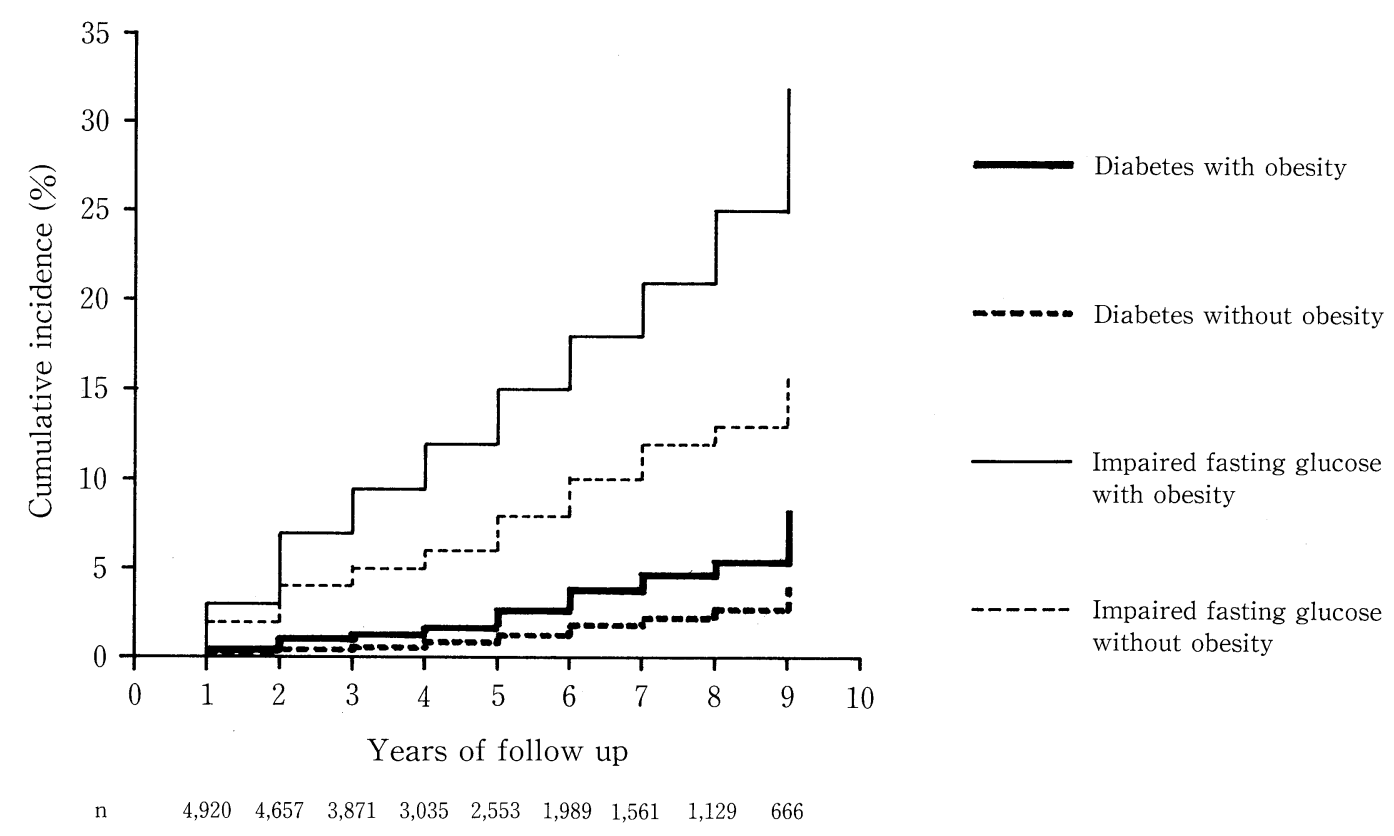

Figure 1. Incidence of newly developed impaired fasting glucose and diabetes in obesity and non-obesity.

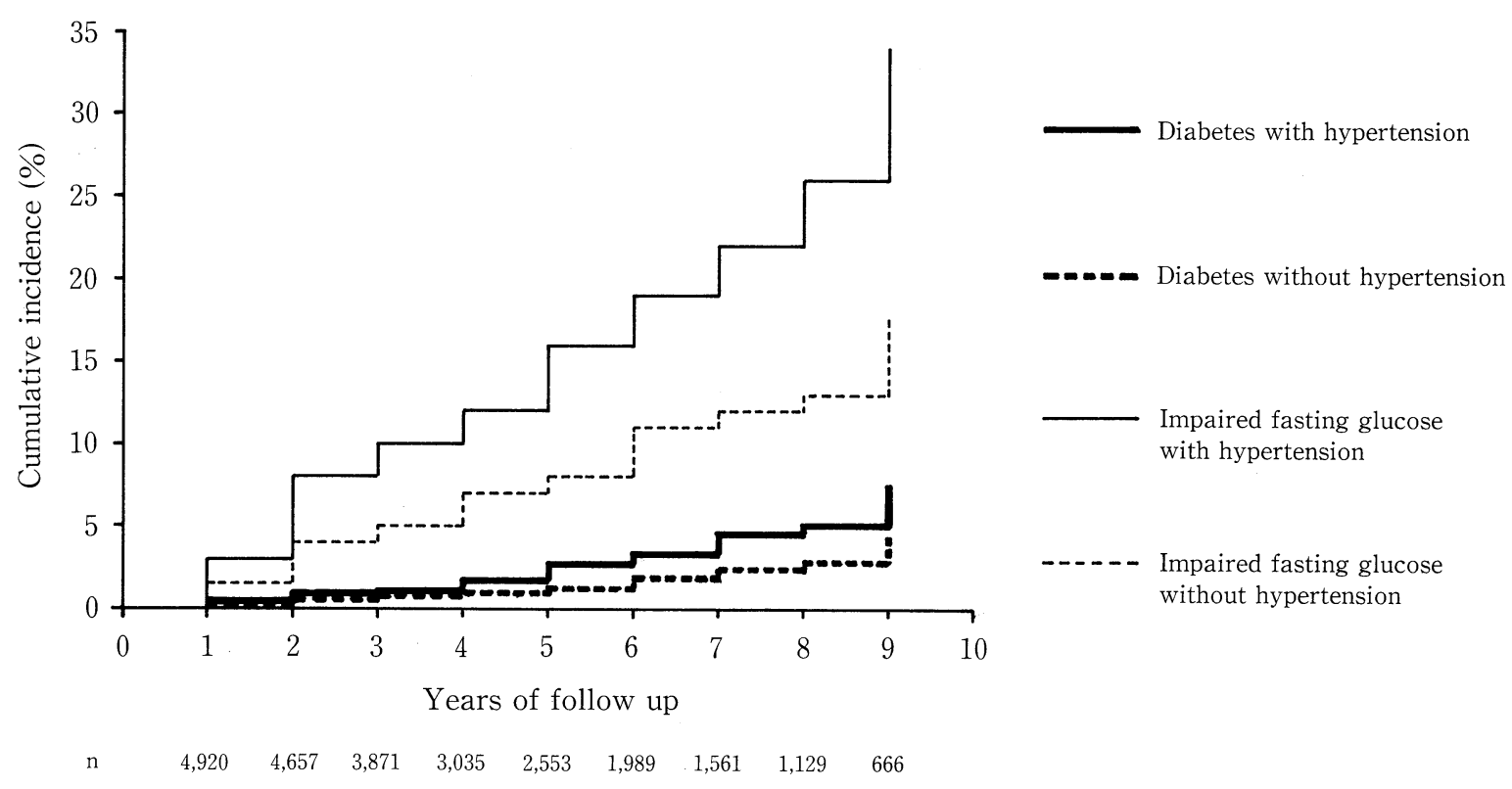

Figure 2. Incidence of newly developed impaired fasting glucose and diabetes in hypertension and normotension.

nificant Hazard ratio. However, the levels of body mass index and triglyceride had 1.30 -fold $(95 \%$ CI $1.02-1.16, \mathrm{p}=0.003)$, and 1.003-fold (95\% CI 1.001-1.005, $\mathrm{p}=0.013$ ) risk for the development of diabetes mellitus (Table 3).

\section{Discussion}

In other studies, the incidence of the development of impaired glucose tolerance and diabetes mellitus has ranged from 15 to $45 \%$ for over 10 years $(15,23,24)$. In this study, the cumulative incidences of development of impaired fasting glu- 


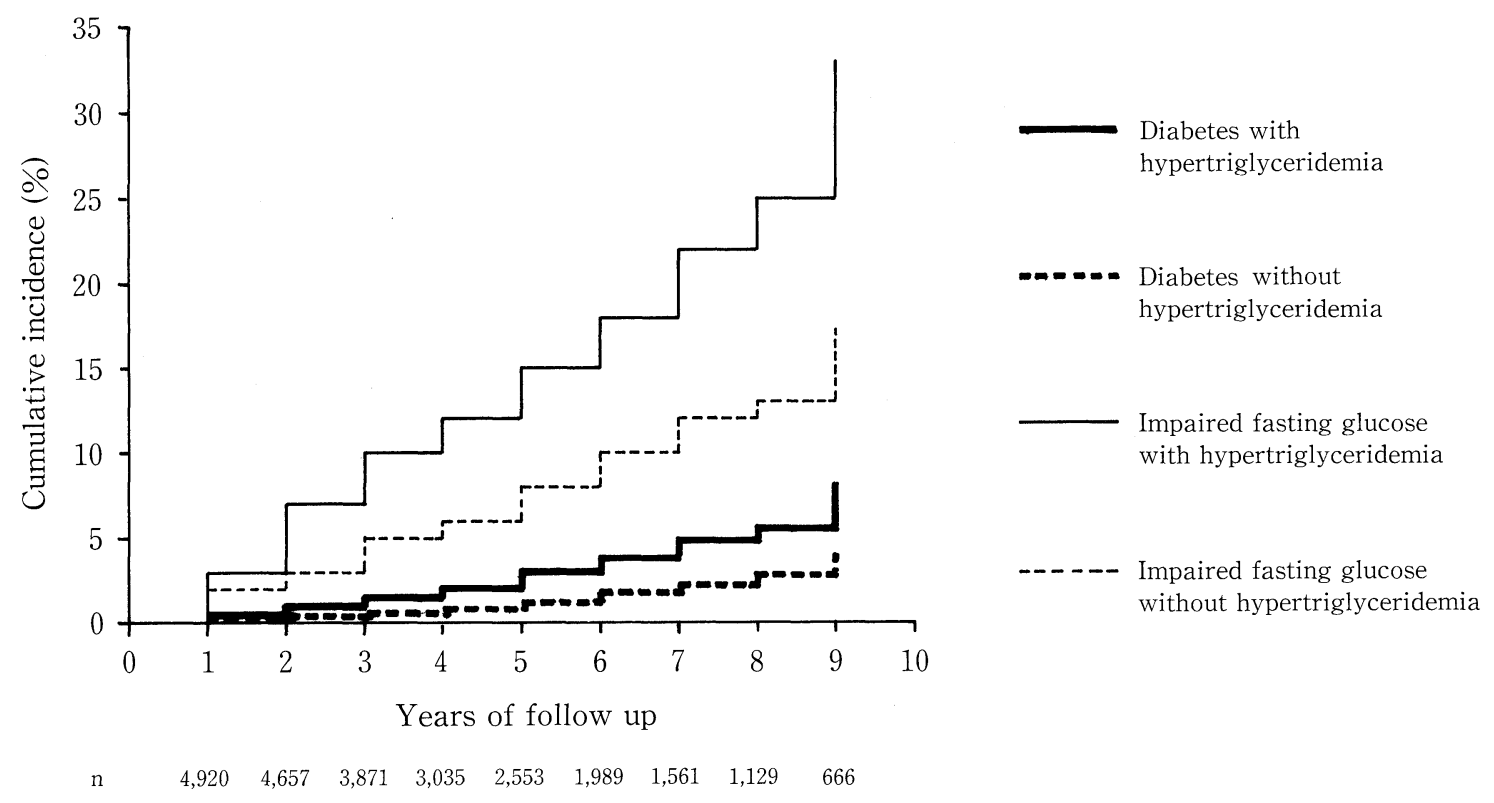

Figure 3. Incidence of newly developed impaired fasting glucose and diabetes in hypertriglyceridemia and normotriglyceridemia.

Table 2. Cox Regression Model of Impaired Fasting Glucose Incidence, Adjusted for Age, Obesity, Hypertension, and Hypertriglyceridemia

\begin{tabular}{lccc}
\hline & Hazard ratio & $95 \% \mathrm{CI}$ & p-value \\
\hline Age & 1.009 & $1.001-1.018$ & 0.035 \\
Obesity & 1.30 & $1.09-1.55$ & 0.003 \\
Hypertension & 1.29 & $1.07-1.55$ & 0.007 \\
Hypertriglyceridemia & 1.38 & $1.15-1.66$ & 0.001 \\
Sex & 0.91 & $0.76-1.01$ & $\mathrm{~ns}$ \\
Fasting plasma glucose & 1.38 & $1.14-1.16$ & 0.001 \\
at baseline (mg/dl) & & & \\
Family history of DM & 1.26 & $1.03-1.56$ & 0.027 \\
\hline
\end{tabular}

Table 3. Cox Regression Model of Diabetes Mellitus Incidence, Adjusted for Age, Obesity, Hypertension, and Hypertriglyceridemia

\begin{tabular}{lccc}
\hline & Hazard ratio & $95 \% \mathrm{CI}$ & $\mathrm{p}$-value \\
\hline Age & 1.02 & $1.00-1.04$ & 0.046 \\
$\mathrm{BMI}\left(\mathrm{kg} / \mathrm{m}^{2}\right)$ & 1.30 & $1.02-1.16$ & 0.003 \\
Hypertension & 1.21 & $0.79-1.87$ & $\mathrm{~ns}$ \\
Triglyceride $(\mathrm{mg} / \mathrm{dl})$ & 1.003 & $1.001-1.005$ & 0.013 \\
Sex & 0.79 & $0.51-1.23$ & $\mathrm{~ns}$ \\
Fasting plasma glucose & 1.19 & $1.16-1.23$ & 0.001 \\
at baseline (mg/dl) & & & \\
Family history of DM & 2.38 & $1.59-3.57$ & 0.001 \\
\hline
\end{tabular}

cose and diabetes mellitus in 9 years were respectively $20 \%$ and $4.5 \%$. We have shown that hypertriglyceridemia, obesity, hypertension, and age were the independent risk factors for the development of impaired fasting glucose in the Japanese. Also, hypertriglyceridemia and obesity were independent risk factors for the development of diabetes mellitus. However, hypertension was not an independent risk factor for the development of diabetes mellitus.

A family history of diabetes, obesity, hypertension, insulin resistance, low insulin secretion, low physical activity, and cigarette smoking are known risk factors for type 2 diabetes and impaired fasting glucose (25-28). Clustering of dyslipidemia, diabetes, obesity, and hypertension was reported in many crosssectional studies. These risk factors for diabetes mellitus are related to insulin resistance (29). In those reports, fasting hyperinsulinemia was an independent risk factor. In this study, obesity, hypertriglyceridemia, and hypertension had independence. Therefore, it could be suspected that not only insulin resistance but also other mechanisms are the fundamental risks for impaired fasting glucose and diabetes mellitus.

The level of fasting glucose in normal fasting glucose was an independent risk factor for the development of impaired fasting glucose and diabetes mellitus. Impaired fasting glucose has a high prevalence of impaired glucose tolerance. $(30,31)$. Similar progression rates to diabetes are reported in impaired glucose tolerance/normal fasting glucose and impaired fasting glucose/normal glucose tolerance groups. In impaired glucose tolerance/ impaired fasting glucose, the progression rate to diabetes is two fold $(11,32)$.

Hypertension was an independent risk factor for the development of impaired fasting glucose in this study. Otherwise, 
hypertension was not an independent risk factor for the development of diabetes mellitus. This suggests that impaired fasting glucose and diabetes mellitus correspond to different stages of impaired glucose metabolism (15). Impaired fasting glucose has hyperinsulinemia whereas diabetes mellitus has low insulin secretion (33). Hypertension is more strongly related to hyperinsulinemia.

In this study, subjects with hypertriglyceridemia were significantly more obese and had a significantly higher blood pressure and higher glucose concentration than subjects without hypertriglyceridemia at baseline. However, after adjusting for BMI, hypertension, and fasting glucose at baseline hypertriglyceridemia were independent risk factors for the development of impaired fasting glucose and diabetes mellitus. But hypertriglyceridemia was not a risk factor for diabetes mellitus in the Paris prospective study (12). Perphaps, this is because the duration of follow-up in the Paris study was only 3 years and thus too short to evaluate the risk factors for diabetes mellitus. In the Framimgham study, very low density lipoproteins and obesity were independent predictors of glucose intolerance for a 14-year follow-up period (11). In that study however, diabetes mellitus was not differentiated from impaired glucose tolerance. The fasting triglyceride level was positively associated with the 2-hour glucose level in the oral glucose tolerance test after 6 years in Chinese (20). However, half of the subjects in their study already had impaired glucose tolerance at baseline. In the present study, all subjects had normal fasting glucose at baseline. In a small group of familial hypertriglyceridemia patients, the level of serum triglyceride was an independent predictor for the development of impaired glucose tolerance and type 2 diabetes (34). Moreover, our study showed that hypertriglyceridemia was an independent risk factor for the development of impaired fasting glucose and diabetes mellitus in the general Japanese population. Triglyceriderich lipoproteins and free fatty acids may directly interfere with peripheral binding and the action of insulin (35-37); an increased hepatic flux of free fatty acids may also increase hepatic glucose production (38). In recent reports, obesity and type 2 diabetes have been associated with low plasma adiponectin concentrations; adiponectin decreases insulin resistance by decreasing the triglyceride content in muscle and liver in obese mice $(39,40)$. Adiponectin may also have an important role for the development of diabetes mellitus.

In conclusion, hypertriglyceridemia is an independent risk factor for the development of impaired fasting glucose and diabetes mellitus in Japanese. In the future, the relationship between hypertriglyceridemia and the pathogenesis of diabetes mellitus should be studied.

\section{References}

1) Avellone G, Di Garbo V, Panno AV, De Simone R, Raneli G, Strano A. Prevalence of diabetes mellitus and of associated risk factors for atherosclerosis in a randomized population sample of western Sicily. Casteldaccia study. Int Angiol 8: 97-101, 1989.

2) Scragg R, Baker J, Metcalf P. Factors associated with development of diabetes mellitus: results from a cross sectional survey in Kawerau. $\mathrm{N} \mathrm{Z}$
Med J 103: 575-577, 1990.

3) Schmidt MI, Watson RL, Duncan BB, et al. Clustering of dyslipidemia, hyperuricemia, diabetes, and hypertension and its association with fasting insulin and central and overall obesity in a general population. Atherosclerosis Risk in Communities Study Investigators. Metabolism 45: 699-706, 1996.

4) Chen $\mathrm{CH}$, Lin KC, Tsai ST, Chou P. Different asssociation of hypertension and insulin-related metabolic syndrome between men and women in 8437 nondiabetic Chinese. Am J Hypertens 13: 846-853, 2000.

5) Resnick HE, Shorr RI, Kuller L, Franse L, Harris TB. Prevalence and clinical implications of American Diabetes Association-defined diabetes and other categories of glucose dysregulation in older adults. The Health, Aging and Body Composition Study. J Clin Epidemiol 54: 869-876, 2001.

6) Lim SC, Tai ES, Tan BY, Chew SK, Tan CE. Cardiovascular risk profile in individuals with borderline glycemia: the effect of the 1997 American Diabetes Association diagnostic criteria and the 1998 World Health Organization Provisional Report. Diabetes Care 23: 278-282, 2000.

7) Fisman EZ, Motro M, Tenenbaum A, Boyko V, Mandelzweig L, Behar S. Impaired fasting glucose concentrations in nondiabetic patients with ischemic heart disease: a marker for a worse prognosis. Am Heart J 141: 485-490, 2001.

8) Alexander CM, Landsman PB, Teutsch SM. Diabetes mellitus, impaired fasting glucose, atherosclerotic risk factors, and prevalence of coronary heart disease. Am J Cardiol 86: 897-902, 2000.

9) Hanefeld M, Koehler C, Henkel E, Fuecker K, Schaper F, TemelkovaKurktschiev T. Post-challenge hyperglycaemia relates more strongly than fasting hyperglycaemia with carotid intima-media thickness: the RIAD Study. Risk Factors in Impaired Glucose Tolerance for Atherosclerosis and Diabetes. Diabet Med 17: 835-840, 2000.

10) Tominaga $M$, Eguchi $H$, Manaka $H$, Igarashi $K$, Kato T, Sekikawa $A$. Impaired glucose tolerance is a risk factor for cardiovascular disease, but not impaired fasting glucose. The Funagata Diabetes Study. Diabetes Care 22: 920-924, 1999.

11) Larsson H, Lindgarde F, Berglund G, Ahren B. Prediction of diabetes using ADA or WHO criteria in post-menopausal women: a 10-year follow-up study. Diabetologia 43: 1224-1228, 2000.

12) Bunnag P, Chanprasertyothin S, Kongsuksai A, Ongphiphadhanakul B, Rajatanavin R, Puavilai G. Correlation between serum insulin and features of metabolic syndrome in Thais. J Med Assoc Thai 83: 783-789, 2000.

13) Bog-Hansen E, Lindblad U, Bengtsson K, Ranstam J, Melander A, Rastam L. Risk factor clustering in patients with hypertension and non-insulindependent diabetes mellitus. The Skaraborg Hypertension Project. J Intern Med 243: 223-232, 1998.

14) Snehalatha C, Sivasankari S, Satyavani K, Vijay V, Ramachandran A. Insulin resistance alone does not explain the clustering of cardiovascular risk factors in southern India. Diabet Med 17: 152-157, 2000.

15) Morales PA, Mitchell BD, Valdez RA, Hazuda HP, Stern MP, Haffner SM. Incidence of NIDDM and impaired glucose tolerance in hypertensive subjects. The San Antonio Heart Study. Diabetes 42: 154-161, 1993.

16) Skarfors ET, Lithell HO, Selinus I. Risk factors for the development of hypertension: a 10-year longitudinal study in middle-aged men. J Hypertens 9: 217-223, 1991.

17) Lissner L, Bengtsson C, Lapidus L, Kristjansson K, Wedel H. Fasting insulin in relation to subsequent blood pressure changes and hypertension in women. Hypertension 20: 797-801, 1992.

18) Wilson PW, McGee DL, Kannel WB. Obesity, very low density lipoproteins, and glucose intolerance over fourteen years: The Framingham Study. Am J Epidemiol 114: 697-704, 1981.

19) Charles MA, Fontbonne A, Thibult N, Warnet JM, Rosselin GE, Eschwege E. Risk factors for NIDDM in white population. Paris prospective study. Diabetes 40: 796-799, 1991.

20) Iimura O. Background of cardiovascular diseases in adult-with special reference to metabolic disorder of glucose and hypertension. Jpn J Geriat 31: 1-9, 1994.

21) Hayashi T, Tsumura K, Suematsu C, Endo G, Fujii S, Okada K. High normal blood pressure, hypertension, and the risk of type 2 diabetes in Japanese men. The Osaka Health Survey. Diabetes Care 22: 1683-1687, 


\section{Risk Factors for IFG and Diabetes Mellitus}

1999.

22) The Expert Committee on the Diagnosis and Classification of Diabetes mellitus: Report of the Expert Committee on the Diagnosis and Classification of Diabetes mellitus. Diabetes Care, 20: 1183-1197, 1997 (see comments).

23) Lillioja S, Mott DM, Howard BV, et al. Imparred glucose tolerance as a disorder of insulin actıon: longitudinal and cross-sectional studies in Pıma indians. N Engl J Med 318: 1217-1225, 1988.

24) Nakanıshi N, Nakamura K, Matsuo Y, Suzuki K, Tatara K. Cigarette smoking and risk for impaired fasting glucose and type 2 diabetes in middleaged Japanese men. Ann Intern Med 133: 183-191, 2000.

25) Haffner SM, Miettinen H, Stern MP. Are risk factors for conversion to NIDDM similar in high and low risk populations? Diabetologia 40: 6266, 1997.

26) Strandberg TE, Salomaa V. Factors related to the development of diabetes during a 20-year follow-up. A prospective study in a homogeneous group of middle-aged men. Nutr Metab Cardiovasc Dis 10: 239-246, 2000.

27) Yang $\mathrm{W}$, Xing $\mathrm{X}$, Lin H. Baselıne hypertriglyceridemıa, a risk factor for non-insulin dependent diabetes mellitus: a 6-year follow-up study of 432 nondiabetics. Chung Hua Nei Ko Tsa Chih 34: 583-586, 1995.

28) Guthrie JR, Ball M, Dudley EC, et al. Impaired fasting glycaemia in middle-aged women: a prospectıve study. Int J Obes Relat Metab Disord 25: 646-651, 2001.

29) Haffner SM, Valdez RA, Hazuda HP, Mitchell BD, Morales PA, Stern MP. Prospective analysis of the insulin-resistance syndrome (syndrome X). Diabetes 41: 715-722, 1992.

30) Pan WH, Yeh WT, Hwu CM, et al. Undiagnosed diabetes mellitus in Taiwanese subjects with imparred fasting glycemia: impact of female sex, central obesity, and short stature. Chin J Physiol 44: 44-51, 2001.

31) Weyer C, Bogardus C, Pratley RE. Metabolic characteristics of individu- als with impaired fastıng glucose and/or impaired glucose tolerance. Diabetes 48: 2197-2203, 1999.

32) Gabir MM, Hanson RL, Dabelea D, et al. The 1997 American Diabetes Association and 1999 World Health Organization criteria for hyperglycemia in the diagnosis and prediction of diabetes. Diabetes Care 23: 1108$1112,2000$.

33) Guerrero-Romero F, Rodriguez-Moran M. Impaired glucose tolerance is a more advanced stage of alteration in the glucose metabolism than $1 \mathrm{~m}-$ paired fasting glucose. J Diabetes Complications 15: 34-37, 2001.

34) Sane T, Taskinen MR. Does familial hypertriglyceridemia predispose to NIDDM? Diabetes Care 16: 1494-1501, 1993.

35) Bieger WP, Michel G, Barwich D, Biehl K, Wirth A. Diminished insulin receptors on monocytes and erythrocytes in hypertriglycerıdemia. Metabolısm 33: 982-987, 1984.

36) Randle PJ, Garland PB, Hales CN, Newsholme EA. The glucose fattyacid cycle: its role in insulin sensitivity and metabolic disturbances of diabetes mellitus. Lancet 1: 785-789, 1963.

37) Svedberg J, Bjorntorp P, Lonnroth P, Smith U. Prevention of Inhibitory effect of free fatty acıds on insulın binding and action in isolated rat hepatocytes by etomoxır. Diabetes 40: 783-786, 1991.

38) Golay A, Swislocki AL, Chen Y-Di, Reaven GM. Relationships between plasma free fatty acid concentration, endogenous glucose production, and fasting hyperglycemia in normal and non-insulin-dependent diabetic individuals. Metabolısm 36: 692-696, 1987.

39) Weyer $C$, Funahashi T, Tanaka $S$, et al. Hypoadiponectinemia in obesity and type 2 diabetes: close association with insulin resistance and hyperinsulınemia. J Clin Endocrinol Metab 86: 1930-1935, 2001.

40) Yamauchi $T$, Kamon J, Waki H, et al. The fat-derived hormone adiponectin reverses insulin resistance associated with both lipoatrophy and obesity. Nat Med 7: 941-946, 2001. 